\title{
Europe will win from integration
}

Written by: Stefano Scarpetta, Director, Directorate for Employment, Labour and Social Affairs, OECD and Jean-Christophe Dumont, Head of International Migration Division, Directorate for Employment, Labour and Social Affairs, OECD

Last update: 16 June 2016

The unfolding refugee crisis requires a bold, comprehensive and global response. At the same time, OECD countries should adapt their policies to foster the integration of those who are going to stay. While this implies significant up-front costs, it is also essential to reaping sizeable medium- to long-term social and economic benefits.

(left to right) Stefano Scarpetta, Director, OECD Directorate for Employment, Labour and Social Affairs; Jean-Christophe Dumont, Head of International Migration Division, OECD Directorate for Employment, Labour and Social Affairs

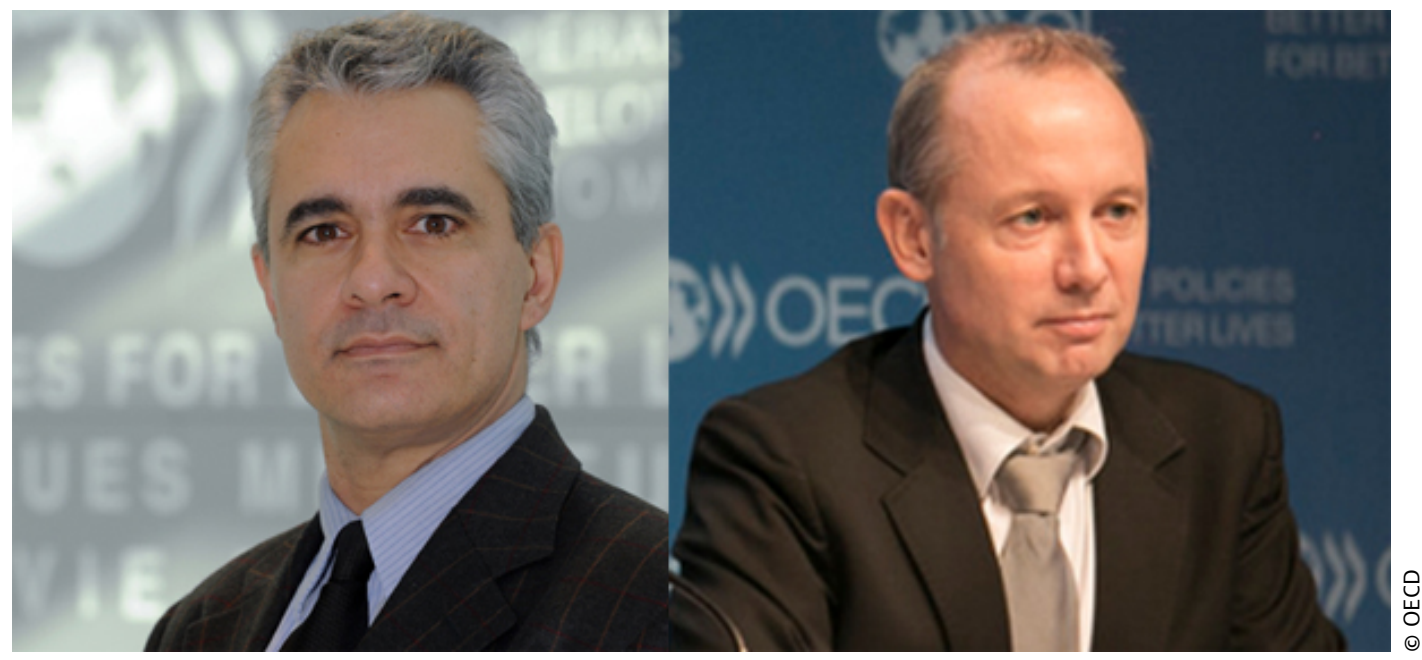

Europe and the Middle East are in the depths of an unprecedented humanitarian crisis, with an appalling and unacceptable human cost. Countries neighbouring Syria host almost 5 million Syrians, while the European Union faces persistent pressure on both its external borders and its asylum system. With twice as many asylum applications in 2015 as in the previous year, the number of refugees in Europe is unparalleled in recent times.

Much of the public focus is on the large inflows of Syrian refugees to Europe. In reality, however, Syrians accounted for less than a quarter of all asylum applications in the OECD in 2015; since January 2016, they have made up less than 
a half of all those on boats between Turkey and Greece. So where are the asylum seekers coming from? In France, the main country of origin in 2015 was Sudan; in the United Kingdom and Switzerland, it was Eritrea; in Finland, it was Iraq; in Italy, it was Nigeria followed by Pakistan. In Sweden, Germany and Denmark, Syria was on top, but in Sweden, Afghanistan took second place, while in Germany, it was Albania, and in Denmark, it was Iran.

It is also important to note that only a few countries in Europe have been deeply affected by the crisis, most notably the main entry points-Italy and Greece but also Slovenia and Hungary-and some key destination countries, in particular Germany, Sweden and Austria. Other countries have been much less exposed or have only recently experienced a significant increase in asylum seekers.

The diversity of nationalities, motives for migration and individual profiles of asylum seekers, as well as the concentration of inflows in just a few countries, has created a major challenge for asylum systems and welcoming communities in Europe. This has affected much-needed co-ordination at EU and international level.

The limited prospect for significant improvement in the near future in Syria and Libya also fuels anxiety. Amid the destruction of several cities and continuing political uncertainty, millions of Syrians could still be displaced. The situation in Libya also remains unsettled, with a strong presence of well-organised smuggling networks, connected to armed Islamic groups, ensuring smuggling routes remain open in the central Mediterranean.

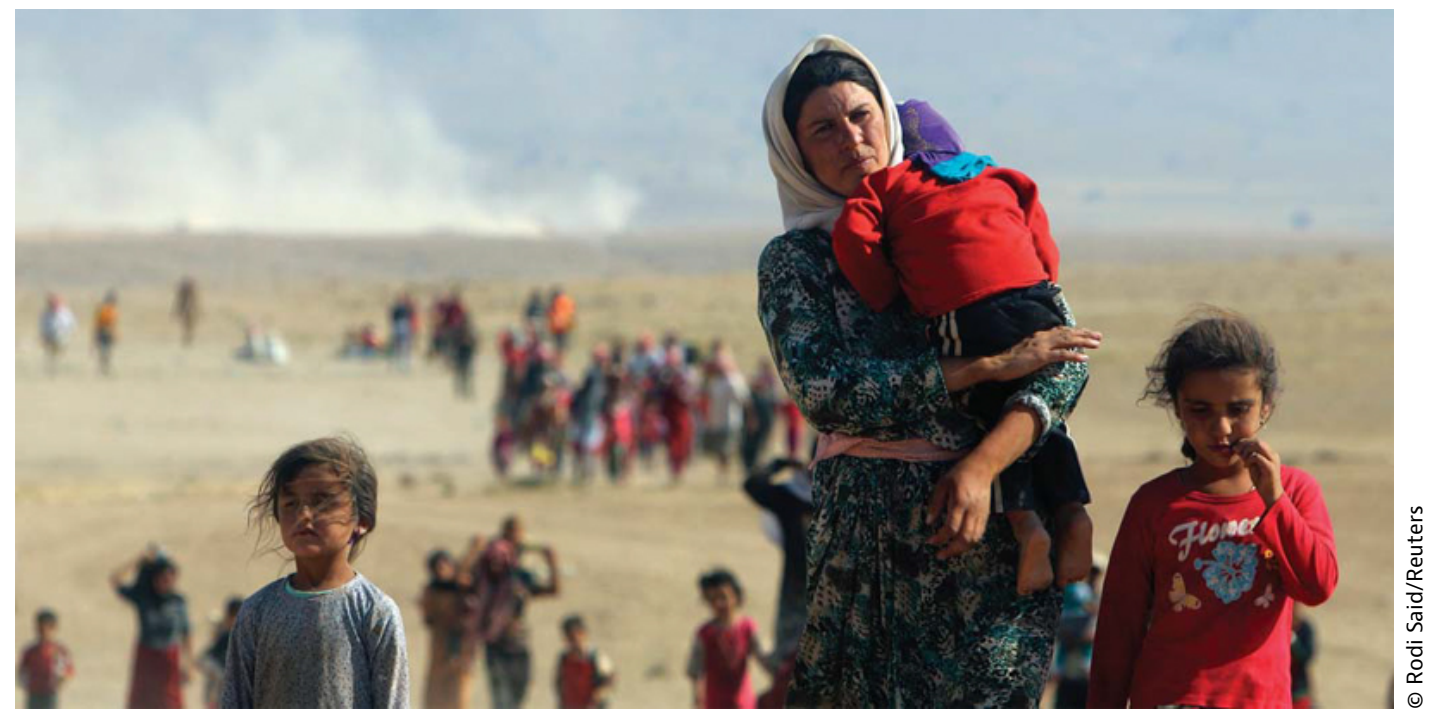

\section{Can Europe cope?}

Today, Europe is becoming a major destination for legal labour migrants. But, over the decades, it has also experienced several unexpected mass influxes of asylum seekers and refugees. In the 1970s, it was the Vietnamese boat people; in the 1990s, people forced out by wars in the former Yugoslavia; and in the early 2000s, 
people fleeing wars in Iraq and Afghanistan. The closest historical parallels with today's crisis-albeit only in terms of scale-are the inflows of French and Portuguese repatriates in the 1960s and 1970s or the arrival of more than 3 million ethnic Germans in the late 1980s and early 1990s in Germany.

European countries were typically caught off guard by these large and unexpected flows. But they also generally coped successfully, managing to integrate those migrants who remained. In many cases, countries also benefited economically, at least in the longer run. Today, the challenges are daunting, but Europe has both the capacity and the experience to respond to the current crisis.

To do so, however, it needs to get its policy response right. So far, the main policy focus has been on saving lives at sea; providing emergency support to refugees and asylum seekers; reinforcing border controls; improving international coordination and burden-sharing mechanisms and improving co-ordination mechanisms with origin and transit countries. These actions are key and need to be further pursued and in some cases reinforced. But it is essential that they are also complemented by measures aimed at fostering the integration of those refugees and their children who are likely to stay in the host country. Action is also needed to start rebuilding trust on migration issues and to combat smuggling networks and corruption associated with irregular migration.

\section{Integration-we can do it}

To the question of whether or not we can integrate refugees, the answer is clear: We can. Even more importantly, we should! Successful integration not only brings economic and fiscal benefits, it is also an important factor in fostering social cohesion.

To the question of whether or not we can integrate refugees, the answer is clear: We can. Even more importantly, we should!

Nevertheless, it is clear that the challenges of integration are significant. Among the most pressing is the need to scale up assistance to cope with the rapidly increasing inflows of refugees. But successful integration also requires comprehensive, well-tailored measures that take account of a refugee's country of origin, educational background, and family situation. As refugee flows increase and grow more diverse, integration policy instruments must be increasingly customised.

Integration is complicated by the trauma that many migrants have suffered, as well as by the fact that most had little time to prepare their departure. Complicating things still further are poor language skills and a lack of documents certifying their level of competences. A substantial investment is needed at first to allow refugees to settle and develop their skills. Many European countries already have introduction programmes for refugees, but, in many cases, these need to be scaled up. They also need to be available through the country, to be 
tailored to refugees' needs and to be accessible as soon as possible, even before the end of the recognition procedure. The recent report Making Integration Work: Refugees and others in need of protection (OECD, 2016) provides many examples of good practices and policy lessons to help countries take up the challenge.

New asylum seekers in the OECD, the EU and Germany

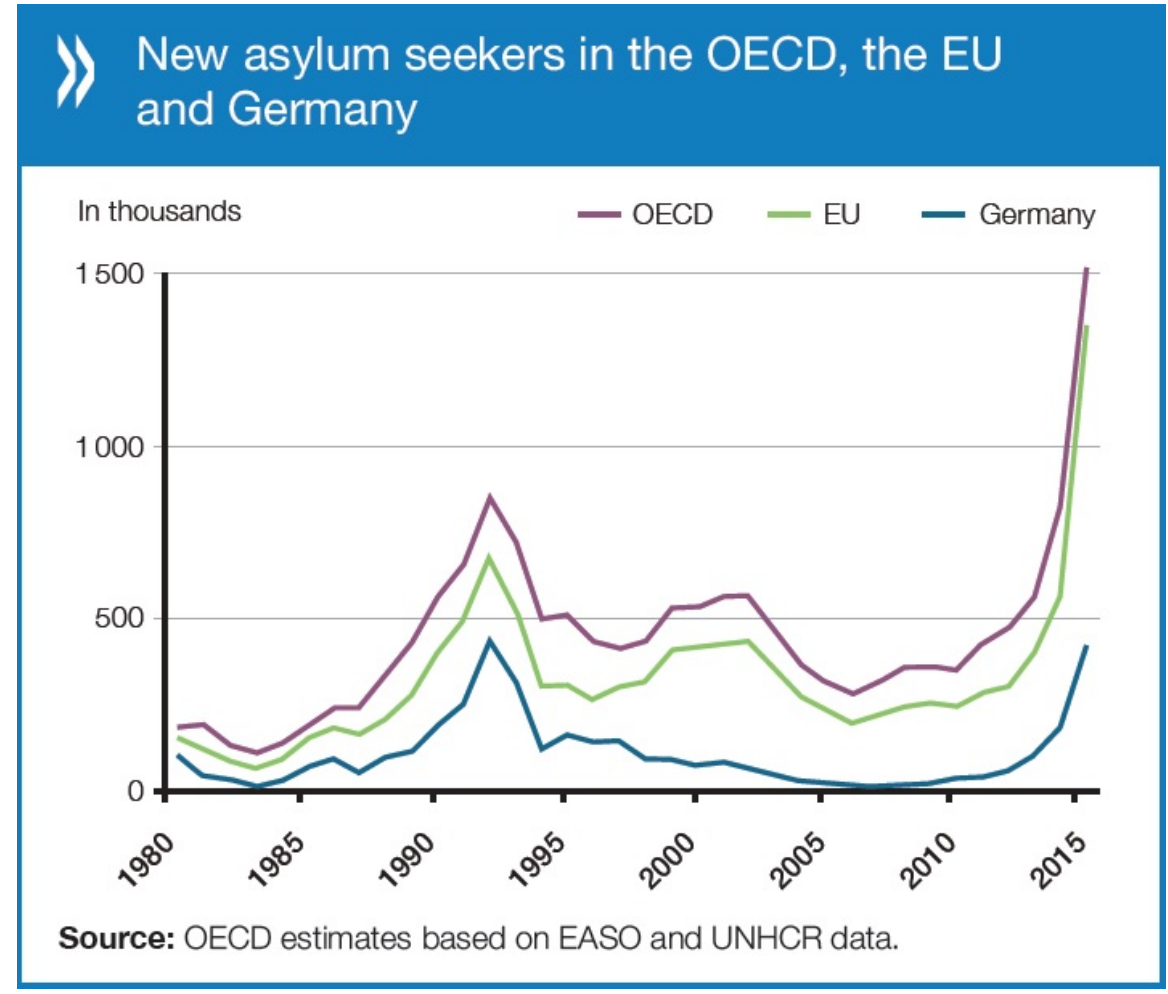

OECD

Looking to the future of migration In the absence of a crystal ball, no one can say for sure how this crisis will unfold in 2016. However, it is unlikely that the inflows will stop. What can be said for certain is that this crisis has revealed weaknesses in migration-management systems that need to be addressed.

No single European country can handle such a large humanitarian crisis alone; nor can Europe act alone. There must be a global response. The European Union should work closely with countries of origin and transit to address the issue. International co-operation is needed to curb irregular movements through intelligence sharing, co-ordinated actions against smuggling networks, organised returns and the development of information campaigns. At the same time, more must be done to further develop orderly migration channels and the management of international mobility.

Dealing with the current refugee crisis, and addressing future challenges associated with migration as a result of ongoing demographic and geopolitical changes, will require a new approach to migration. This approach needs to be more proactive, comprehensive and regional, and to focus more on crisis 
prevention than on crisis resolution. Now comes the time for this strategic reflection to take place at the international level.

Visit www.oecd.org/migration-insights

\section{References}

Making Integration Work http://dx.doi.org/10.1787/9789264251236-en 